\section{Der Richter und sein - Psychiater}

\section{H. Lachenmeier}

Es herrschte Nebel, wie oft in jenem Spätherbst, und eigentlich war er an der Türe schon vorbeigegangen, als er doch wieder zurückkehrte. Er trat in meine Praxis und begrüsste mich mit den Worten: "Als Richter habe ich hie und da mit Psychiatern zu tun. Ich habe keinen guten Eindruck. Ich bin misstrauisch. Aber ich habe Angstattacken. So muss ich wohl zu Ihnen.»

Ich fragte ihn, ob er selbst etwas gegen die Attacken unternehmen wolle oder ob ihn jemand zwinge. Und als er seinen Willen betonte, wollte ich wissen, weshalb er denn für seine Probleme den Vertreter eines Berufsstandes aufsuchte, von dem er nichts halte.

Irritiert und zunehmend nervös schaute er mich an.

So nahm die Behandlung ihren Anfang. Ein Prozess ohne Richter. Zuweilen machte sich in ihm eine Wut bemerkbar, die ihn tief ängstigte, der er auswich, die er gerade als Richter nicht gelten lassen wollte.

Seine Tochter wurde langsam erwachsen. Er liebte sie. Jahrelang hatte er sie beschützt. Über sie gewacht. Mit angstvoll heimlicher Wut quittierte er ihre Unabhängigkeit. Seit einem halben Jahr stritten sie nun.

Schmerzlich wurde er gewahr, wie widersprüchlich seine Gefühle waren. Was er seiner Tochter vorenthielt. Allmählich wagte er es, sie nicht mehr zu kontrollieren. Erstaunt und mit erstem, neuem Glück realisierte er den Rückgang der Streitereien. Von neuem kamen sie sich näher, ohne Kontrolle.

Später traten Gefühle zu seinem Sohn nach vorne. Auch dort fand er Liebe und Wut, Angst und Kon-

Korrespondenz:

Dr. med. Heiner Lachenmeier

Breitenstrasse 20

CH-8910 Affoltern am Albis

hlachenmeier@datacomm.ch trolle, bis hin zur Lähmung. Mit Mut überwand er diesen Berg. Es kam der Tag, da sich beide ihre eigenen Wege lassen konnten.

Noch immer war er Richter. Musste weiterhin urteilen. Richten. Jahrelang hatte das sein Leben bestimmt. Er war immer direkt. Untrüglich gerecht nach dem Gesetz. Seine Integrität hatte ihn stets gehindert, seinen Beruf als sportliches Feld eines Wettbewerbs zu betrachten, mit Karriereschritten als Ziel. Es war ihm ein tiefes Anliegen, Recht zu sprechen. Ein guter Richter.

Diesen Kern bewahrte er. Sein Einsatz für Gerechtigkeit hielt an. Und doch hatte er sich geändert. Er wurde weicher. Nicht weniger konsequent, nein wärmer. Weiterhin mit klarem, messerscharfem Verstand, aber mit mehr Anteilnahme.

Eines Tages, im Sommer danach, besuchte er mich und erzählte: Immer wieder muss er Fälle behandeln, in denen sich Nachbarn über der Höhe von Bäumen, dem Lärm der Rasenmäher und den überhängenden Obststauden in die Haare geraten. Zwanzig Jahre lang hatte er das rasch erledigt. 1,80 $\mathrm{m}$ ist die Limite, also runter mit der Baumkrone. Juristisch korrekt und gerecht.

Jetzt bemerke er, was er all die Jahre nicht wirklich wahrgenommen habe: die haben Streit. Da schwelt ein menschlicher Konflikt. Heute rede er mit den Leuten, und recht oft gelinge es nach längerem Gespräch, ohne einen Richterspruch auszukommen. An seinem Gericht habe er heute eine der höchsten Rate an Vergleichen.

Er geniesse es, wenn nach einer solchen Verhandlung weder ein Gewinner noch ein Verlierer feststehe, sondern zwei zufriedene Nachbarn, die miteinander reden. Nur: nach solchen Verhandlungen sei er müde. Viel müder als früher, als er sich auf $1,80 \mathrm{~m}$ konzentriert habe.

Ach ja, und die Angstattacken seien verflogen. Aber das sei fast nebensächlich. Die schnellere Müdigkeit störe ihn wenig. Früher, als er mechanisch gerecht gewesen sei, wäre er eben kaum müde geworden. Doch Menschen werden müde.

Mit erhobenem Kopf ging er langsam hinaus.

Der Psychiater sass später im Sprechzimmer, ohne aufzustehen, ohne sich zu erheben. Nicht mal ein Jahr, dachte er, nicht mal eines Jahres bedurfte es, um die Lebenskraft zu wecken. Dann machte er sich auf den Heimweg. 